\title{
Hyperemesis Gravidarum: A Holistic Review and Approach to Etiopathogenesis, Clinical Diagnostic and Management
}

\section{Therapy}

Tigor P Simanjuntak ${ }^{1}$, Samuel A Andrian ${ }^{2}$, Rian Wibowo ${ }^{3}$, Stella A Kurniawan ${ }^{4}$, Ni MU Elingasari ${ }^{5}$

\begin{abstract}
Aim: To provide an overview of hyperemesis gravidarum $(\mathrm{HG})$ and to present possible links between factors associated with the pathogenesis of $\mathrm{HG}$ also the effectiveness and safety of the nonpharmacologic and pharmacologic options available to treat $\mathrm{HG}$.

Background: Although HG incidence is $0.3-2 \%$ worldwide, it is the number one cause of hospitalization in the first-trimester pregnancy, costs greatly to one financially, and also reduces the quality of life. This literature review focuses on articles published over the last 7 years to examine current perspectives and recent developments in HG.

Review results: Nausea and vomiting are common symptoms during early pregnancy. When vomiting is severe, it is referred to as HG. Despite its high prevalence, it tends to be underestimated. The etiopathogenesis remains unknown, but many risk factors have been determined. Currently, the therapy focused on improving the symptoms while minimizing risks to the mother and fetus. If HG is left untreated, it may lead to significant maternal morbidity and adverse birth outcomes.

Conclusion: Hyperemesis gravidarum is a complex and multifactorial condition. The incidence is higher in developing countries rather than in developed countries. Hyperemesis gravidarum can manifest as mild to severe signs and symptoms. The therapy ranges from dietary and lifestyle changes, intravenous fluid rehydration, hospitalization, nonpharmacologic, and pharmacologic treatment. Hyperemesis gravidarum can result as a mild to severe maternal and fetal complications.
\end{abstract}

Keywords: Etiopathogenesis, Hyperemesis gravidarum, Incidence, Outcomes, Treatment.

Journal of South Asian Federation of Obstetrics and Gynaecology (2019): 10.5005/jp-journals-10006-1700

\section{BACKGROUND}

Hyperemesis gravidarum (HG) is excessive vomiting in pregnancy starting before the end of the 22 nd week of gestation with or without metabolic disturbance such as carbohydrate depletion, dehydration, and electrolyte imbalance. ${ }^{1}$ The most commonly cited criteria for the diagnosis of $\mathrm{HG}$ include persistent vomiting ${ }^{2-8}$ (more than three times a day ${ }^{9}$ ) that is unassociated with other medical conditions, ${ }^{4}$ dehydration ${ }^{2-8}$ such as dry skin and lethargy, ${ }^{7}$ ketonuria, ${ }^{5-8,10}$ electrolyte imbalance (hypokalemia and hyponatremia), ${ }^{2,4-8,10,11}$ and weight loss more than $5 \%$ of prepregnancy body weight. $4,6-8,10$ Hyperemesis gravidarum incidence is $0.3-2 \%$ worldwide, but the number one cause of hospitalization in the first-trimester of pregnancy and costs greatly to one financially, ${ }^{12}$ and also reduces the quality of life. ${ }^{13}$

Several risk factors associated with hyperemesis have been reported, such as nulliparity, juvenile pregnancy, multiple pregnancies, an anomaly of the fetus, female fetus, history of HG and other complications in a previous pregnancy, gastrointestinal tract infection, patient psychology factor, dysmenorrhea, and body weight. 2,3,13-15 Etiology and pathophysiology of HG are certainly unknown. 2,3,5,16,17 Several etiologies have been suspected play a role in $\mathrm{HG}$, including elevated human chorionic gonadotropin (hCG), $3,4,7,8,11$ estrogen, progesterone, ${ }^{3,4,7}$ prostaglandin E2 (PGE2), ${ }^{3,4}$ gastric dysmotility, ${ }^{3,4}$ immunology, and inflammation ${ }^{3,8}$ also infection of Helicobacter pylori. ${ }^{3,4,7,8}$ Recent several studies show relations between $\mathrm{HG}$ and mild to severe maternal and fetal outcomes. $5,10,16,18,19$

First-line treatments of HG consist of simple lifestyle changes (eating small amounts often, avoid stimulating foods

\footnotetext{
${ }^{1-5}$ Department of Obstetrics and Gynecology, Faculty of Medicine, Christian University of Indonesia, Jakarta, Indonesia
}

Corresponding Author: Tigor P Simanjuntak, Department of Obstetrics and Gynecology, Faculty of Medicine, Christian University of Indonesia, Jakarta, Indonesia, Phone: +62 8121105912, e-mail: tigorpsimanjuntak@gmai.com

How to cite this article: Simanjuntak TP, Andrian SA, Wibowo R, et al. Hyperemesis Gravidarum: A Holistic Review and Approach to Etiopathogenesis, Clinical Diagnostic and Management Therapy. J South Asian Feder Obst Gynae 2019;11(4):266-272.

Source of support: Nil

Conflict of interest: None

such as spicy foods, fatty foods, avoid stress, and get as much rest as possible), ${ }^{20-24}$ doxylamine/pyridoxine combination, ${ }^{20-23}$ ginger and acupressure at the pericardium P6 point. ${ }^{20,23,24}$ Second-line treatments include a range of antiemetic drugs (metoclopramide, antihistamines, phenothiazines, and ondansetron $)^{20,23}$ also additional drugs such as antacids, $\mathrm{H} 2$ antagonists and proton-pump inhibitors (PPIs) ${ }^{21}$ as well as the provision of intravenous fluid and electrolyte replacement for women who are dehydrated and ketotic. ${ }^{22}$ Third-line treatments are reserved for patient with severe and persistent symptoms. These include corticosteroids and supportive therapy, such as enteral or parenteral feeding. ${ }^{20,23,24}$ This journal review focuses on articles published over the last 7 years to examine current perspectives and recent developments in HG. 


\section{Definition}

Hyperemesis gravidarum is excessive vomiting in pregnancy starting before the end of the 22nd week of gestation with or without metabolic disturbance such as carbohydrate depletion, dehydration, and electrolyte imbalance. ${ }^{1}$ Hyperemesis gravidarum is the most severe form of nausea and vomiting in pregnancy, and many cases require hospital admission and continuous treatment, ${ }^{18}$ accompanied by more than $5 \%$ body weight loss, disturbance of electrolyte balance, ketonuria ( $80 \mathrm{mg} / \mathrm{dL}$ on urinary dipstick), and dehydration. ${ }^{25-27}$ Excessive vomiting, use vomiting more than three times a day as their standard. ${ }^{26,27}$

\section{InCIDENCE AND RISK Factors}

Nausea and vomiting is a common symptom that happens in $50-90 \%$ pregnancies, and at least $1 / 3 \mathrm{rd}$ of the incidences need further treatment. ${ }^{28}$ Meanwhile, HG incidence is only $0.3-2 \%$ worldwide. Hyperemesis gravidarum shows a variant incidence presentation in every country, wherein Swedish $0.3 \%$, Norwegian $0.9 \%$, Canada $0.8 \%$, Malaysia $3.9 \%$, and China $10.8 \% .{ }^{14}$ Some studies show a higher incidence in some ethnic groups. ${ }^{7,14,28}$ In 8 million pregnancies, $61 \%$ are white, followed by Asian with $17 \%$ of the total. ${ }^{26}$ Hyperemesis gravidarum population in East Asia itself is 3.9\%. ${ }^{14}$ In Indonesia, HG in pregnancy reachs $14.8 \% .{ }^{29}$ Even though it doesn't show a significant number of incidences, HG is the number one cause of hospitalization in the first-trimester pregnancy and costs greatly to one financially, ${ }^{12}$ also reduces the quality of life. ${ }^{13}$ Before 1940, HG caused maternal death in a significant number. ${ }^{29}$ Based on the data taken in Indonesia; there is a significantly increased number of incidence of obstetric complications, included $\mathrm{HG}^{30}$

From 8 million pregnant women, HG common occurrence obtained at 25-29 weeks gestation, followed by 20-24 weeks gestation. ${ }^{31}$ Most HG patients had normal body mass index (BMI) (BMI 18.5-24.9), nonsmoking, with formal education $>15$ years. Mothers with low socioeconomic condition also have a higher incidence of HG. ${ }^{14}$

Several risk factors associated with hyperemesis have been reported, such as nulliparity, juvenile pregnancy, multiple pregnancies, an anomaly of the fetus, female fetus, history of HG and other complications in previous pregnancy, gastrointestinal tract infection, patient psychology factor, dysmenorrhea, and body weight. ${ }^{2,3,13-15}$ Recent research suggests that gemili with both female fetuses may further aggravate the degree of HG.

There is a difference saying between journals was journal from Egypt writes that $94.6 \%$ of HG occurs in the first trimester (6-12 weeks), although in international journals it is said that HG in nulliparas mother happens more in their first trimester, whereas in multipar in the second trimester. ${ }^{14,32}$

Hyperemesis gravidarum tends to happen more in female fetuses. Female fetus has a higher level of ketonuria and a higher incidence of hospitalization. Some theory suggests that hCG levels at maternal levels are higher in the presence of female fetuses. There is no difference in serum urea level and hospitalization terms and reoccurrence in both. ${ }^{7}$ For the male fetus, association with an increase in premature risk and neonatal morbidity is found. ${ }^{33}$ It should be noted that the percentage of HG incidence in female and male fetuses didn't show a significant difference. ${ }^{19,28,31,33}$

There is an association between HG and a heavier weight of the placenta compared with birth weight. Female fetus gender also found as exacerbates factors. ${ }^{19}$ Primary dysmenorrhea is defined as pain during menses in the absence of an identifiable pathologic lesion, which usually begins during adolescence. There is an association between adolescent and adult dysmenorrhea and HG. ${ }^{15}$

Psychological factors such as depression, anxiety, and stress are closely related to HG, but whether psychological factors are a risk factor or as a result of HG is still debatable. Some studies say that the effects of psychological abnormalities are only temporary and will disappear, 18 months after birth, some say the psychological disorder is settled and requires special attention to treatment. ${ }^{34-36}$ However, psychiatric factors do not increase the risk of recurrent events for HG. ${ }^{37}$

H. pylori should be considered as one of the risk factors of HG, especially in developing countries. $H$. pylori is believed to have a contribution to the persistence of nausea and vomiting beyond the normal time course, dysmotility of the gastrointestinal tract and prolonged gastric emptying, and intestinal transit time. H. pylori infected the stomach of $50 \%$ of the world population, and it is more prevalent in developing countries. ${ }^{38}$

Results of a study implicated both underweight (BMI $5-20 \mathrm{~kg} / \mathrm{m}^{2}$ ) and obese prepregnancy BMl is a significantly increased risk of developing $\mathrm{HG}$. Inadequate weight gain in the first trimester, as assessed by comparison of pre-pregnancy BMI and BMI during the first trimester, has been significantly associated with HG. In obesity, visceral adipose tissue (VAT) and prepregnancy BMI were correlated with the development of HG and hence could be considered as predictive markers for HG. Visceral adipose tissue is considered more specific than subcutaneous fat tissue (SCC). ${ }^{39}$

More than $28 \%$ of women with HG experienced recurrent events in the same pregnancy, and $26 \%$ experienced $\mathrm{HG}$ again in subsequent pregnancies. There was no association between HG and the longterm mortality of the fetus, as well as the risk of cardiovascular disease during adolescence. ${ }^{33,40}$ In conclusion, HG is a complex, multifactorial condition with many potential etiological factors. ${ }^{39}$

\section{Signs and Symptoms of Hyperemesis Gravidarum}

Nausea and vomiting in pregnancy could be persistent and severe enough to require hospitalization to prevent maternal and fetal morbidity, this condition is known as HG. ${ }^{2,3,7}$ Specific diagnostic criteria for HG are lacking, ${ }^{7,8}$ but from several studies, the most commonly cited criteria for diagnosis of HG include persistent vomiting ${ }^{2-8,10}$ (more than three times a day ${ }^{9}$ ) that unassociated with other medical conditions ${ }^{4}$, dehydration ${ }^{2-8}$ such as dry skin and lethargy, ${ }^{7}$ ketonuria, ${ }^{2-8,10}$ electrolyte imbalance (hypokalemia and hyponatremia), ${ }^{2,4-8,10,11}$ weight loss more than $5 \%$ of pre pregnancy body weight $4,6,7,10$ and severe signs and symptoms including orthostatic hypotension, tachycardia ${ }^{7}$, hypovolemia, ${ }^{10}$ muscle wasting, ${ }^{2}$ mood changes and lethargy, ${ }^{7}$ elevated from amylase, lipase, and functioning liver enzyme, ${ }^{6,7}$ and an increase in hematocrit. ${ }^{6}$ Severity of HG can be marked with the presence of severe ketonuria, ${ }^{74}(\geq+3),{ }^{9,41}$ need for hospital admission, ${ }^{2,3,41}$ early admission ( $<10$ weeks of gestation), need total parenteral nutrition (TPN), and duration of hospitalization more than 2 days. ${ }^{41}$

\section{Etiology and Pathophysiology of Hg}

Several studies have proposed to show that the etiology of HG is multifactorial. ${ }^{2,4,7}$ Several factors have been suspected to play role of etiopathogenesis $\mathrm{HG}$, including elevated of $\mathrm{hCG}^{3,4,7,8,11}$ estrogen, ${ }^{3,4,7}$ progesterone, ${ }^{3,4,7}$ PGE2, gastric dysmotility, , $^{3,4}$ immunology, and inflammation ${ }^{3,8,17}$ and infection of H. pylori. . $^{3,4,7,8}$ 


\section{Human Chorionic Gonadotropin}

Several studies have suggested that hCG indirectly causes HG by inducing thyroid hormones through thyroid-stimulating hormone (TSH) and estrogen (hormones are known to induce gestational emesis) by luteinizing hormone (LH). ${ }^{3,4}$ One research from Dypvik et al. found mean maternal hCG serum concentrations in singleton pregnancies are $122 \mathrm{IU} / \mathrm{L}$ and $234 \mathrm{IU} / \mathrm{L}$ in twin pregnancies. ${ }^{11}$ Another research from Garshabi et al. showed mean hCG serum concentrations in singleton pregnancies without $\mathrm{HG}$ and with HG is $150 \mathrm{IU} / \mathrm{L}$ and $210 \mathrm{IU} / \mathrm{L} .{ }^{42}$ In research from Atmaca et al., mean hCG serum concentrations in women with HG are 114 IU/L. ${ }^{9}$ Research from Ghazali et al. showed mean hCG serum concentrations in women with $\mathrm{HG}$ are $173 \mathrm{IU} / \mathrm{L} .{ }^{43}$ According to that several research, $\mathrm{HG}$ typically present in a range of mean $\mathrm{hCG}$ serum concentrations between $114 \mathrm{IU} / \mathrm{L}$ and $210 \mathrm{IU} / \mathrm{L}$ in singleton pregnancies, while mean hCG serum concentrations in twin pregnancies is $234 \mathrm{IU} / \mathrm{L}$.

\section{Estrogen and Progesterone}

Research from Al Ghazali et al. showed mean estradiol serum levels in patients with $\mathrm{HG}$ are $2,090 \mathrm{pg} / \mathrm{mL} .{ }^{43}$ Several proposed mechanisms of estrogen and progesterone are decreased gastric emptying, overall intestinal transit time, ${ }^{3,7}$ gastric dysrhythmias, decreasing gastric smooth muscles contractility, ${ }^{3,4,7}$ reducing intestinal motility, lower esophageal sphincter (LES) tone relaxation. , $^{3,4}$

\section{Prostaglandin E2}

Several studies have been shown a strong relationship exists between serum levels of PGE2 with HG. ${ }^{3,4}$ PGE2 was found to affect $\mathrm{HG}$ by regulating gastric slow-wave frequency and peristaltic. ${ }^{3}$

\section{Gastrointestinal Dysmotility}

Pregnant women with HG have a more unstable electrogastrogram (EGG) activity than pregnant women without HG or nonpregnant women. Changes in EGG activity have been associated with clinical symptoms of HG. ${ }^{4,6}$

\section{Immunology and Inflammation}

During pregnancy, there is an increase in certain subsets of immune cells (granulocyte, natural killer cell, and T cells), 3,17 interleukin 4, interleukin 6 (IL-6), tumor necrosis factor a, immunoglobulin IgG and $\mathrm{IgM}$, and complements have been found to be increased in $\mathrm{HG}^{3,17}$ Research from Desdicioglu et al. showed a significant increase of soluble urokinase-type plasminogen activator receptor (suPAR) and IL- 6 in women with HG compared to women without HG as a control group. ${ }^{17}$ According to that study results, increased levels of suPAR and IL- 6 in HG group could be suggested associated with the etiopathogenesis of HG. That supported by some conditions such as steroid-using in HG patients shows dramatic improvement of the symptoms. ${ }^{17,43}$

\section{H. pylori}

Incidence of $H$. pylori infection in women with HG is about $90 \%{ }^{4}$ In terms of the role of $H$. pylori on the pathogenesis of $H G$, it has been suggested that $H$. pylori may exacerbate hormone-induced changes in the nerve and electric functioning of the stomach. Local inflammation and produces toxins from colonizes bacterium are inducing severe vomiting in HG. Pathogenic strain from $\mathrm{H}$. pylori is cytotoxin-associated gene A (CagA gene) that produces CagA protein, which induces mucosal damage and causes peptic ulcers. In this context, several studies reported that CagA positivity is more prevalent in patients with $\mathrm{HG}^{8}$

\section{Laboratory Findings and Diagnosis}

The most commonly cited criteria for the diagnosis of HG include persistent vomiting not related to other causes, an objective measure of acute starvation (usually large ketonuria on urine analysis), electrolyte abnormalities, and acid-base disturbances such as hypochloremic alkalosis, hypokalemia, and hyponatremia, as well as weight loss.,20,22,44 Ultrasound examination may confirm viability and gestational age also identify a predisposing factor such as multiple pregnancies or molar gestation. ${ }^{2,20,45}$

Nausea and vomiting in HG can be categorized based on its severity using a validated questionnaire, known as pregnancyunique quantification of emesis and nausea (PUQE) scoring index shown in Table 1.7,20,22,46 Nausea and vomiting are categorized into three classes, mild, moderate, and severe. The total score is summed from the answers of each three questions. Categorized as mild, when the score is $<6$, moderate with a score of $7-12$, and severe with a score of $>13$. Whereas from another literature, $\mathrm{HG}$ can be classified clinically into the level I, II, and III based on symptoms and physical examination. ${ }^{8}$

\section{Management of Hyperemesis Gravidarum}

Hospitalization is considered in patients with severe and persistent vomiting, weight loss, ketonuria, dehydration, and electrolyte disturbance. ${ }^{22,47,48}$ Patients who are dehydrated and unable to take oral medications or fluids require intravenous fluid therapy. ${ }^{20,45}$ The use of normal saline/ $\mathrm{NaCl} 0.9 \%$ and ringer lactate (RL) is preferably ${ }^{21,48,49}$ compared to dextrose because dextrose increases the incidence of Wernicke's encephalopathy. ${ }^{21,44}$ Supplementation with thiamine $100 \mathrm{mg}^{7,21,48}$ may prevent the occurrence of Wernicke's encephalopathy. ${ }^{7,20,45}$ Nutrition with enteral tube feeding (nasogastric, nasojejunal) was initiated in refractory cases, patients who were unresponsive to drug therapy and unable to maintain their weight. ${ }^{22,44,46}$ Total parenteral nutrition was given to patients who did not respond to antiemetic therapy and can't be managed with enteral nutrition. ${ }^{45,49}$

\section{Nonpharmacological Therapy of Hyperemesis Gravidarum}

Mild cases of nausea and vomiting of pregnancy may be resolved with lifestyle and dietary changes. Common dietary recommendations include consumption of bland foods, eat small meals but often, avoid an empty stomach, avoid spicy and fatty foods, ${ }^{2,20,22,46-50}$ give time between eating and drinking as well as drinking small and frequently. ${ }^{46,48,49}$ Lifestyle modification involves

Table 1: Modified pregnancy unique quantification of emesis and nausea (PUQE) $)^{20}$

\begin{tabular}{llllll}
\hline & 1 & 2 & 3 & 4 & 5 \\
\hline $\begin{array}{l}\text { Nauseated or stom- } \\
\text { achache }\end{array}$ & Not at all & $<1$ hour & $2-3$ hours & $4-6$ hours & $>6$ hours \\
Vomit & - & $1-2$ times & Times & 5-6 times & $>7$ times \\
Dry heaves & - & $1-2$ times & $3-4$ times & times & $>7$ times \\
\hline
\end{tabular}


identifying and avoiding the triggers of nausea and vomiting, ${ }^{20,44}$ preventing stress, and taking rest as much as possible. ${ }^{20,46,49}$

Psychotherapy and replacing iron-free multivitamins with folic acid supplementation may be recommended. ${ }^{20,22,47-50}$ ACOG recommends ginger as a nonpharmacological intervention ${ }^{20,44}$ that can improve nausea but not to reduce vomiting. ${ }^{20-22,49}$ Ginger contains gingerol and shogaol that inhibit 5-HT3 serotonergic receptors and inhibit the growth of $H_{\text {. pylori. }}{ }^{45,50}$ Ginger available in powder, capsule, tablet, and syrup ${ }^{37}$ with recommended doses of $250 \mathrm{mg} 4$ times daily peroral. ${ }^{45,50}$ Ginger is found to be safe without an increase in major malformation. ${ }^{20,46-50}$ Acupressure therapy in relieving nausea and vomiting, which performed on the pericardium 6 (P6/neiguan), ${ }^{24,50}$ remains controversial. ${ }^{45}$

\section{Pharmacological Therapy of HG}

The effectiveness and safety of many optional medicines, shown in Table 2, are taken into consideration in the selection of pharmacological therapy for HG cases.

In the past, thalidomide was prescribed for the treatment of HG worldwide, especially in Europe, but the United States FDA rejected thalidomide in 1962 when the drug was released in 1957 because

Table 2: Fetal safety of pharmacologic agents used to treat nausea and vomiting of pregnancy ${ }^{44}$

\begin{tabular}{|c|c|c|}
\hline \multirow{2}{*}{$\begin{array}{l}\text { Pharmacologic class/ } \\
\text { agent }\end{array}$} & \multicolumn{2}{|c|}{ Risk classification } \\
\hline & FDA risk factor & Briggs et al. \\
\hline $\begin{array}{l}\text { Doxylamine suc- } \\
\text { cinate/pyridoxine } \\
\text { hydrochloride }\end{array}$ & A & Compatible \\
\hline \multicolumn{3}{|l|}{ H1-receptor blocker } \\
\hline Dimenhydrinate & Not rated & Compatible \\
\hline Diphenhydramine & Not rated & Compatible \\
\hline Doxylamine & Not rated & Compatible \\
\hline Meclizine & Not rated & Compatible \\
\hline Hydroxyzine & Not rated & $\begin{array}{l}\text { Human data suggest } \\
\text { low risk }\end{array}$ \\
\hline Meclizine & Not rated & Compatible \\
\hline Metoclopramide & B & \\
\hline \multicolumn{3}{|l|}{ Phenothiazine } \\
\hline Prochlorperazine & Not rated & Compatible \\
\hline Promethazine & $\mathrm{C}$ & Compatible \\
\hline Ondansetron & B & $\begin{array}{l}\text { Human data suggest } \\
\text { low risk }\end{array}$ \\
\hline $\begin{array}{l}\text { Pyridoxine hydro- } \\
\text { chloride }\end{array}$ & A & Compatible \\
\hline Corticosteroid & $\mathrm{C}$ & $\begin{array}{l}\text { Human data suggest } \\
\text { risk; avoid during } \\
\text { first } 10 \text { weeks of } \\
\text { gestation }\end{array}$ \\
\hline
\end{tabular}

Note: A: adequate and well-controlled human studies have failed to demonstrate a risk to the fetus in the first trimester of pregnancy (and there is no evidence of risk in later trimester); B: animal reproduction studies have failed to demonstrate a risk to the fetus and there are no adequate and well-controlled studies in pregnant women or animal studies have shown an adverse effect, but adequate and well-controlled studies in pregnant women have failed to demonstrate a risk to the fetus in any trimester; C: animal reproduction studies have shown an adverse effect on the fetus and there are no adequate and well-controlled studies in humans, but potential benefits may warrant use of drug in pregnant women despite potential risks of its teratogenic effect that could cause congenital abnormalities of phocomelia. ${ }^{8}$ ACOG recommends a combination of vitamin B6 (pyridoxine) and $\mathrm{H} 1$ antagonists (doxylamine) as a safe and effective first-line pharmacotherapy (category A). ${ }^{20,45-47,49}$ Metoclopramide and promethazine have similar effectiveness in reducing nausea and vomiting, but the side effects are lower in the use of metoclopramide. ${ }^{20,21,45,48}$ Antihistamines or $\mathrm{H} 1$ receptor antagonists such as dimenhydrinate and diphenhydramine (category B) that work indirectly to the vestibular system by reducing stimulation in the vomiting center are also frequently used and proven to be effective without risk to the fetus. ${ }^{20,22,50}$ The use of metoclopramide, promethazine, or antihistamines during pregnancy does not increase the risk of congenital malformation. ${ }^{20-22,45,47}$

5-hydroxytryptamine3 (5HT3) receptor antagonists such as ondansetron are beginning to be used frequently. Ondansetron has the same effectiveness as promethazine and metoclopramide, but its side effects are smaller. ${ }^{20,45}$ Several studies have reported the occurrence of cleft palate and heart defects, on the use of ondansetron ${ }^{48,50}$ methylprednisolone may be an option for refractory cases. ${ }^{20,21,45,50}$ In one study, it was found that the use of methylprednisolone in the first trimester was associated with cleft palate risk. ${ }^{7,20,22,45-47,49,50}$ Steroid use should be avoided before 10 weeks of gestation. ${ }^{20,45,49,50} \mathrm{H} 2$ receptor antagonists such as ranitidine (category $\mathrm{B}$ ), and PPI such as omeprazole (category C), are often used for reflux management when antacids failed to overcome. Its use is unrelated to an increased risk of major malformations. ${ }^{21,47,50}$

\section{Therapeutic Treatment of Nausea and Vomiting of Pregnancy}

Therapeutic treatment assumes other causes of nausea and vomiting have been ruled out. At any step, consider enteral nutrition if dehydration or persistent weight loss is noted.

- Some antiemetic medications have only been approved by the US Food and Drug Administration for use in nonpregnant patients; however, off-label use is common. Obstetricians and other obstetric care providers should counsel patients and document such discussions accordingly. Care should be exercised if multiple antiemetic medications are used simultaneously. Parallel use of some medications (see text) may result in an increased risk of adverse effects.

- In the United States, doxylamine is available as the active ingredient in some over-the-counter sleep aids; one half of a scored $25 \mathrm{mg}$ tablet can be used to provide a $12.5 \mathrm{mg}$ dose of doxylamine.

- Thiamine, intravenously, $100 \mathrm{mg}$ with the initial rehydration fluid and $100 \mathrm{mg}$ daily for the next 2-3 days (followed by intravenous multivitamins), is recommended for women who require intravenous hydration and have vomited for more than 3 weeks to prevent a rare but serious maternal complication, Wernicke encephalopathy. ${ }^{20}$

\section{Hyperemesis Complications Maternal Complications}

Several maternal complications from HG such as severe malnutrition, ${ }^{2,3,7}$ anemia, ${ }^{18}$ Wernicke's encephalopathy ${ }_{1}^{4,7,10}$ peripheral neuropathy, ${ }^{2-4}$ coagulopathy, ${ }^{2,4,7}$ venous thromboembolism (VTE). ${ }^{9}$ And some rare complications such as acute kidney injury ${ }^{10}$ that marked as oliguria, esophageal rupture, ${ }^{3,4,7}$ Mallory-Weiss 
syndrome, pneumomediastinum, ${ }^{3,7}$ rhabdomyolysis, ${ }^{4,7,10}$ and demyelination syndrome such as central pontine myelinolysis. ${ }^{4,7}$

This deficiency of thiamine or vitamin B1 may lead to a syndrome called Wernicke's encephalopathy. ${ }^{4,7}$ Patients may present with neurological symptoms from lethargy and confusion ${ }^{4,7}$ to hyporeflexia, ${ }^{7}$ ataxia, and oculomotor symptoms including nystagmus and ophthalmoplegia, ${ }^{4,7}$ and convulsion. ${ }^{4}$ If Wernicke's encephalopathy is suspected for a patient, MRI may be useful in the diagnosis and identifying other severe complications such as central pontine myelinolysis. ${ }^{7}$ Central pontine myelinolysis is a demyelinating of the central pons while preserving the axons. This condition present due to prolong hyponatremia and rapid correction of natrium. ${ }^{4}$ A case report patient with HG who got a central pontine myelinolysis that published by Anand et al. has shown upper limits have been set for correction of hyponatremia: 8 $\mathrm{mEq} / \mathrm{L}$ in 24 hours, $14 \mathrm{mEq} / \mathrm{L}$ in 48 hours, and $16 \mathrm{mEq} / \mathrm{L}$ in 72 hours. The pathophysiology of myelinolysis is attributed to hyperosmotic stress produced by rapid correction of hyponatremia, which causes endothelial injury and damages the blood-brain barrier resulting in release of myelinotoxic factors.

Coagulopathy is present from vitamin K deficiency. ${ }^{4,7}$ Peripheral neuropathy is also present due to vitamin B6 and B12 deficiency. ${ }^{4}$ VTE and acute kidney injury that is present in HG can be caused due to prolonged dehydration. ${ }^{18}$ Several studies have shown rhabdomyolysis caused by hypokalemia. ${ }^{4,7,9}$ In severe cases, rhabdomyolysis can cause acute kidney injury by leakage of musclecell contents (myoglobulin) in the urine. ${ }^{4,9}$ Other rare complications of HG are esophageal rupture that marked as hematemesis (known as Mallory-Weiss syndrome) that caused due to repetitive wrenching of gastrointestinal mucosal and barotrauma (Boerhaave syndrome). ${ }^{7}$ Esophageal rupture may lead to complications such as pneumomediastinum (free air in the mediastinum) (Hamman's syndrome). ${ }^{4,7}$ Several studies have been shown relations between HG and depression, anxiety and post-traumatic syndrome. ${ }^{9}$

\section{Fetal Complications}

Hyperemesis gravidarum has been reported to be associated with low birth weight (LBW), ${ }^{3,7,16,18,19}$ preterm birth (PTB), ${ }^{3-8,16,18,19}$ smallfor-gestational-age (SGA), $3,5,8,10,16,18,19$ intrauterine growth restriction (IUGR), ${ }^{5,16}$ preeclampsia, ${ }^{3,5,7,10,18}$ and placental abruption. ${ }^{3,5,7,18} \mathrm{~A}$ recent meta-analysis on $\mathrm{HG}$ and pregnancy outcomes, comprising 13 case-control studies, 10 cohort studies, and one cross-sectional study, reported that $\mathrm{HG}$ was associated with a $30 \%$ increase in risk for PTB and SGA, and 40\% increase in risk for LBW. ${ }^{16}$ Women with $\mathrm{HG}$ gaining less than $7 \mathrm{~kg}$ during pregnancy had a threefold increase in risk for PTB and LBW. ${ }^{3,4,7,16}$ American case-control study found women with $\mathrm{HG}$, to gain on average $4.6 \mathrm{~kg}$ less during pregnancy and to deliver babies, who weighed on average $172 \mathrm{~g}^{5,7}$ to 291 $\mathrm{g}^{16}$ less compared to those born from healthy women. ${ }^{16}$ Other studies showed women with HG more common preterm delivery in gestational age $<37$ weeks ${ }^{7,41}$ with the babies deliver in LBW. ${ }^{16}$

Several studies have been shown that exposure HG in utero associated with risk for the psychological and behavioral disorder ${ }^{4,7,10}$ (attention-deficit disorder, depression, bipolar disorder, and anxiety) and neurodevelopmental disorder ${ }^{4}$ (speech or language delay, social development delay, autism, and central auditory disorder) in children. Overall, $49 \%$ of women with HG reported at least one child with an emotional, behavioral, or learning disorder. The United Kingdom Childhood Cancer Study (UKCCS) found a 3.6-fold increase in risk for all forms of leukemia (acute lymphatic leukemia and acute myeloid leukemia) in children who exposed with HG compared to children who unexposed to HG in utero. An America study reported that hyperemesis was associated with a four-fold increase in testicular cancer risk among male offspring. A possible mechanism is hCG, which increases in $\mathrm{HG}$ can act as a growth factor, and estrogen may also be oncogenic to hematopoietic cells. ${ }^{19}$

According to several data, the most common fetal complications include PTB $<37$ weeks, LBW, and SGA. And the most common fetal long-term complications are depression, anxiety, and bipolar disorder in children who exposed to HG in utero.

\section{Discussion}

There is no exact definition of HG, as it is hard to meet the agreement of excessive vomiting term. Many journals agree that excessive vomiting is the one that causes a metabolic disturbance such as dehydration and electrolyte imbalance, but the WHO states that excessive vomiting could happen with or without metabolic disturbance. To measure excessive vomiting, most journals use vomiting $>3$ times as their standard. Incidence in each country seems to contradict incidence rate based on ethnic, wherein Asian countries show a higher incidence rate, but based on ethnicity, Asian percentage is lower than white people. This happens because the research of ethnic rate was done in a country, where white is the dominant population further, research needs to be done. As for risk factor that affects the most in HG, still, need further research.

Hyperemesis gravidarum is present in the first trimester of pregnancy ${ }^{2-4}$ (starts within 4 weeks after the last menstrual period, ${ }^{3,5}$ and typically peaks around 9 weeks of gestation ${ }^{3,5,6}$ and usually resolves by 12 weeks and 20 weeks of gestation ${ }^{3,4,41}$ ). Clinical research and medical practice have yet to adopt a universal system of HG classification, the clinical diagnosis. ${ }^{7,8}$ However, $\mathrm{HG}$ is clinically classified as mild and severe, whereas a severe symptom is depending on associated metabolic disturbances such as carbohydrate depletion, dehydration, and electrolyte imbalance. ${ }^{2}$ From several signs and symptoms that entered into HG criteria, signs and symptoms of dehydration with or without orthostatic hypotension consistently found in a physical examination in patients with $\mathrm{HG}$.

Progress in the understanding of the etiology and pathophysiology of HG has been slow in recent decades. Until now, there is no major etiopathogenesis, which having strong evidence to cause HG, so that is the multifactorial etiology still believed as a cause of $\mathrm{HG}^{4,8,41}$ A meta-analysis of published studies investigating the correlation between increased serum levels of hCG and HG between 1966 and 2005, noted that out of 18 published studies, 11 showed a positive association. However, direct role of mechanism of $h$ CG causes $H G$ is still unclear. Estrogen and progesterone, which increase dramatically in pregnancy, have also been implicated in the etiopathogenesis of HG. Several studies have shown that some women experience nausea when taking oral contraceptives, which typically contain a combination of estrogen and progesterone. That conditions also support the hypothesis of estrogen and progesterone as an etiology of HG. ${ }^{7}$

Gastrointestinal dysmotility is a condition that causes symptoms of $\mathrm{HG}$, which have an association with hormone estrogen and progesterone. ${ }^{3,4,7}$ The role of immunological homeostasis has also been explored. Functional activation of these cells has been speculated to play a role in pregnancy-associated disorders, including hyperemesis., ${ }^{3,17}$ Pregnancy causes immunological changes, including diminished cell-mediated immunity, hence 
making her more prone to infections, such as $H$. pylori. ${ }^{8} \mathrm{H}$. pylori infection of the stomach has also been associated with an increased incidence of $\mathrm{HG}^{3,7,8}$ A recent study in the Netherlands demonstrated that women who were $H$. pylori positive were more likely to report daily vomiting with an adjusted odds ratio of 1.44. ${ }^{7}$ Another metaanalysis study has shown a significant association between $H$. pylori infection with HG (odds ratio 3.32). ${ }^{10}$

Hyperemesis gravidarum is diagnosed by excluding other causes of the symptoms. ${ }^{7,20,21}$ It is critical to have a graded scale to track the severity of symptoms as a guide to determine the appropriate treatment and response to treatment. Currently, there is no consensus on the definition of $\mathrm{HG}$, and there is no single, widely used set of diagnostic criteria for diagnosing $\mathrm{HG} .{ }^{44}$ Advice for women experiencing NVP has traditionally revolved around dietary changes. However, there is limited evidence supporting the effectiveness of dietary changes on relieving NVP symptoms. Many authors review different classes of antiemetic used to treat this condition and discuss that some have better safety profiles than others, but most appear to be safe to use in pregnancy. Firstly nonpharmacological treatment should be advised. Antiemetic and steroid treatment should be considered latter. ${ }^{2}$ Studies on therapeutics for refractory HG are few in number, suggesting opportunities for further research in this arena. ${ }^{7}$

Hyperemesis gravidarum can cause maternal complications due to electrolyte disturbances, prolonged dehydration, malnutrition, and end-organ damage. ${ }^{8,10}$ Several studies have been shown relations between $\mathrm{HG}$ and depression, anxiety, and posttraumatic syndrome. ${ }^{8,10}$ Psychological and behavioral disorders in women with HG associated with regulation changes of neuroendocrine and neurotransmitters in the brain and abnormal programming of the hypothalamic-pituitary-adrenal axis (HPA-axis). A recent metaanalysis of 37 cohort studies and 18 case-control, including 3.5 million women and other studies reported that low total gestational weight gain was associated with increased risks for PTB, LBW, SGA, and IUGR. ${ }^{4,7,16}$ A research from Peled et al. reported that female fetuses more commonly have IUGR, while male fetuses associated with increased risk for prematurity and neonatal morbidity. ${ }^{41}$ Poor maternal health due to $\mathrm{HG}$ and fetal exposure to hormones induced by HG suggested to play a role of fetal complications in women with $\mathrm{HG} .{ }^{4}$ Also, the most common fetal long-term complications are depression, anxiety, and bipolar disorder in children who exposed to HG in utero.

\section{Conclusion}

Hyperemesis gravidarum is a complex, multifactorial condition with many potential etiological factors. The incidence is higher in developing countries rather than in developed countries. HG can manifest as a mild to severe signs and symptoms due to prolonged dehydration and decrease of nutritional intake that make the patients with HG need for hospitalizations. It is the number one cause of hospitalization in the first-trimester pregnancy. The understanding of the etiopathogenesis of HG remains unclear. But, several studies and research have shown correlations between a number of factors that suggested to play in the role in a etiopathogenesis of $\mathrm{HG}$ with the presence of HG. A focus on the assessment is to confirm that nausea and vomiting are due to the pregnancy and not some other causes. Adoption of an easy, objective and validated tool can be helpful to assess severity and treatment impact such as PUQE. The therapy ranges from dietary and lifestyle changes, intravenous fluid rehydration, hospitalization, nonpharmacologic, and pharmacologic treatment. HG can result in mild to severe maternal and fetal complications.

\section{Clinical Significance}

There were significant results in reducing nausea and vomiting with acupressure therapy. ${ }^{21,22,49,50}$ Some studies have reported that ginger is more effective than a placebo and is as effective as pyridoxine ${ }^{49,50}$ while other studies have found that ginger is more effective than pyridoxine, ${ }^{21}$ but no substantial evidence to suggest that the combination of pyridoxine and doxylamine is more effective than other antiemetic. Metoclopramide is effective, economical, has a long history of widespread use, has an excellent fetal safety record, and remains a reasonable first-line short-term antiemetic choice in HG despite ondansetron. Patients with steroid therapy are less likely to be readmitted. $5,20,44,46,47,49$

\section{References}

1. World Health Organization. International statistical classification of disease and related health problems. 10th rev. WHO 2007 [cited 17 January 2018]. Available from: http://apps.who.int/classifications/ apps/icd/icd10online2007/index.htm?go20.htm.

2. Kamalak Z, Gozukara I, Kucur SK. Is it a disease or a symptom? HG. Eur J Gen Med 2015;12(3):273-276.

3. Mukherjee S, Ross WA, Pan JJ. Nausea and vomiting in pregnancy. McGovern Med Sch J Med 2017;1(2):7-12.

4. Network Continuing Education. HG. Network Continuing Education 2015; $1-20$.

5. Koudijs HM, Savitri Al, Browne JL, et al. HG and placental dysfunction disorder. BMC Pregnancy Childbirth 2016;16(374):1-9.

6. Hughes JD, Nayak NG, Aslam N, et al. Original article: autonomic and enteric nervous system dysfunction may play a role in HG. J Compilation Gastroenterol Res Elmer Press 2015;8(1):153-356. DOI: 10.14740/gr632w.

7. London V, Grube S, Sherer D, et al. HG: a review of recent literature. Pharmacology 2017;100:161-171. DOI: 10.1159/000477853.

8. NGXQ, Venkatanarayanan N, Deyn ML, et al. Original article: a metaanalysis of the association between Helicobacter pylori (H.pylori) infection and HG. Wiley J 2017; 1-11.

9. Lassey SC, Robinson JN. Case report: rhabdomyolysis after HG. Am Coll Obstetricians Gynecol 2016;128(1):195-196. DOI: 10.1097/ AOG.0000000000001418.

10. Atmaca $U$, Atalay $M A$, Ozcimen $N$, et al. Investigating maternal serum thyroid. Hormone, beta-human chorionic gonadotropin (beta-HCG) free beta-HCG Lev HG. Erciyes MedJ 2015;37(4):128-132.

11. Dypvik J, Pereira AL, Tanbo TG, et al. Maternal human chorionic gonadotrophin concentrations in very early pregnancy and risk of HG: a retrospective cohort study of 4372 pregnancies after in vitro fertilization. Eur J Obstet \& Gynecol Reprod Biol 2017;221:12-16. DOI: 10.1016/j.ejogrb.2017.12.015.

12. Kjeldgaard HK, Gran ME, Benth JS, et al. History of depression and risk of HG: a population-based cohort study. Arch Women's Ment Health 2017;20:397-402. DOI: 10.1007/s00737-016-0713-6.

13. Goodwin TM, Ramin SM. Nausea and vomiting of pregnancy. Am Coll Obstet Gynecol 2015;126(3):12-13. DOI: 10.1097/ AOG.0000000000001048.

14. Mahmoud GA. D.N.Sc. prevalence and risk factors of hyperemesis gravidarum among Egyptian pregnant woman at the woman's health center. Med J Cairo Univ 2012;80(2):161-167.

15. Enakpene CA, Dalloul M, Caldwell CP, et al. Dysmenorrhea as a risk factor for hyperemesis gravidarum. J Clin Gynecol Obstet 2015;4(4):283-289. DOI: 10.14740/jcgo356w.

16. Vikanes AV, Stoer NC, Magnus P, et al. HG and pregnancy outcomes in the Norwegian mother and child cohort - a cohort study. BMC Pregnancy Childbirth 2013;13(169):1-8. 
17. Desdicioglu R, Yildirim M, Kocaoglu G, et al. Soluble urokinase-type plasminogen activator receptor (suPAR) and interleukin- 6 levels in HG. J Chin Med Assoc 2017;20:1-5.

18. Fiaschi L, Piercy CN, Gibson J, et al. Adverse maternal and birth outcomes in women admitted to hospital for HG: a population-based cohort study. Paediatric Perinat Epidemiol 2017; 1-10.

19. Vandraas KF, Vikanes AV, Stoer NC, et al. HG and risk of cancer in offspring, a Scandinavian registry-based nested case-control study. BMC Cancer 2015;15(398):1-8.

20. ACOG (American College of Obstetrics and Gynecology) Practice Bulletin. Clinical management guidelines for obstetriciangynecologists no.189: Nausea and vomiting of pregnancy. ACOG Practice Bulletin 2018;131(1):e15-e29.

21. Drug and therapeutic bulletin. Management of HG. Drug Ther Bull 2013;51(11):126-129. DOI: 10.1136/dtb.2013.11.0215.

22. Abramowitz A, Miller ES, Wisner KL. Treatment options for HG. Arch Womens Ment Health 2017;20:363-372. DOI: 10.1007/s00737-016-0707-4.

23. Gunawan K, Manengkei PSK, Ocviyanti D. Diagnosis dan Tata Laksana hiperemesis gravidarum. J Indon Med Assoc 2011;61(11):458-464.

24. McParlin C, O'Donnell A, Robson SC, et al. Treatments for HG and nausea and vomiting in pregnancy $A$ systematic review. JAMA 2016;316(13):1392-1401. DOI: 10.1001/jama.2016.14337.

25. Grooten I, Den HW, Roseboom T, et al. Helicobacter pylori infection: a predictor of vomiting severity in pregnancy and adverse birth outcome. Am J Obstet Gynecol 2017;216(5):512. DOI: 10.1016/j. ajog.2017.01.042.

26. Sadek S, Elmhady M, Elmarsafawy E, et al. Helicobacter pylori infection in cases of HG; updates. J Gynecol Womens Health 2017;4:1-5.

27. Shaban MM, Kandil H, Elshafei AH. Helicobacter pylori seropositivity in patients with HG. Am J Med Sci 2014;347:101-105. DOI: 10.1097/ MAJ.0b013e31827bef91.

28. Fiaschi L, Piercy CN, Tata LJ. Hospital admission for HG: A nationwide study of occurrence, reoccurrence and risk factors among 8.2 million pregnancies. Hum Reprod 2016;31(8):1675-1684.

29. Masruroh S, Si T, Kes M, et al. Hubungan antara umur ibu dan gravida dengan kejadian hiperemesis gravidarum di RSUD Ambawara Kabupaten Semarang. Muswil Ipemi 2016; 204-211.

30. Profil Kesehatan 2014 provinsi Kalimantan Tengah. DINKES provinsi KALTENG. 2014; 44-46.

31. Rashid M, Malik F. Herath RP. HG and fetal gender: a retrospective study. J Obstet Gynecol 2012;32:475-477. DOI: 10.3109/01443615.2012. 666580.

32. Bolin $\mathrm{M}$, Akerud $\mathrm{H}, \mathrm{Cnattingius} \mathrm{S}$, et al. $\mathrm{HG}$ and risks of placental dysfunction disorder: a population-based cohort study. BJOG 2013;120(5):541-547. DOI: 10.1111/1471-0528.12132.

33. Koot MH, Grooten IJ, Sebert S, et al. HG and cardiometabolic risk factors in adolescents: a follow-up of the northern Finland birth cohort 1986. BJOG 2017;124(7):1-7.
34. Jones NM, Gallos I, Farren J, et al. Psychological morbidity associated with hyperemesis gravidarum; a systematic review and meta-analysis. BJOG 2016;124(1):20-30.

35. Tan PC, Zaidi SN, Azmi N, et al. Depression, anxiety, stress and HG: temporal and case controlled correlates. PLoS One 2014;9(3):e92036. DOI: 10.1371/journal.pone.0092036.

36. Kjeldgaard HK, Gran ME, Benth JS, et al. HG and the risk of emotional distress during and after pregnancy. Arch Womens Ment Health 2017;20:747-754. DOI: 10.1007/s00737-017-0770-5.

37. Magtira A, Schoenberg FP, Macgibbon $K$, et al. Psychiatri factors do not affect recurrence risk of HG. J Obstet Gynaecol Res 2014;41(4): 512-516.

38. Li L, Zhou XY, Xiao S, et al. Helicobacter pylori infection is associated with an increased risk of HG: a meta-analysis. Hindawi 2015; $1-10$.

39. Kosus A, Eser A, Kosus N, et al. HG and its relation with maternal body composition. J Obstet Gynaecol 2016;36(6):822-826.

40. Fossum S, Vikanes AV, Vos L, et al. HG and long-term mortality: a population-based cohort study. BJOG 2016;124(7):1080-1087.

41. Peled Y, Melamed N, Hiersch L, et al. Pregnancy outcome in HG - the role of fetal gender. J Maternal-Fetal \& Neonatal Med 2013;26(17):1753-1757. DOI: 10.3109/14767058.2013.798293.

42. Garshasbi A, Ghazanfari T, Zayeri F, et al. Maternal serum levels of interleukin- 6 and $\beta$-hCG in women with HG in the first trimester of pregnancy. J Basic Clin Pathophysiology 2017;5(1):13-18.

43. Al Ghazali BS. Study the association of serum level of $\beta$-hCG and estradiol in the pathogenesis of HG. Int J Med Pharm Sci 2014;4(3): 63-70.

44. Arslan S, Bektas F, Soyincu S. Diagnosis of HG in patients with pregnancy induced vomiting using a point-of-care ketone blood test. Eurasian J Emerg Med 2017;16:119-122. DOI: 10.5152/ eajem.2017.80764.

45. Gunawan K, Manengkei PSK, Ocviyanti D. Diagnosis dan Tata Laksana Hiperemesis Gravidarum. J Indon Med Assoc 2011;61(11):458-464.

46. Niebyl JR. The pharmacologic management of nausea and vomiting of pregnancy. Supplement to the journal of family practice. 2014;63(2):531-537.

47. Maltepe C, Koren G. The management of nausea and vomiting of pregnancy and HG-A 2013 update. J Popul Ther Clin Pharmacol 2013;20(2):e184-e192.

48. Wegrzyniak LJ, Repke JT, Ural SH. Treatment of HG. Rev Obstet Gynecol 2012;5(2):78-84.

49. Castilo MJ, Phillippi JC. HG A holistic overview and approach to clinical assessment and management. J Perinat Neonat Nurs 2015;29(1):12-22. DOI: $10.1097 / J P N .0000000000000075$.

50. Society of Obstetricians and Gynaecologists of Canada (SOGC). The management of nausea and vomiting of pregnancy. J Obstet Gynaecol Can 2016;38(12):1127-1137. DOI: 10.1016/j.jogc.2016.08.009. 